\title{
Burnout among Nurses in a Nigerian General Hospital: Prevalence and Associated Factors
}

\author{
Victor Olufolahan Lasebikan ${ }^{1}$ and Modupe Olusola Oyetunde ${ }^{2}$ \\ ${ }^{1}$ Department of Psychiatry, College of Medicine, University of Ibadan, P.O. Box 31395, Ibadan, Nigeria \\ ${ }^{2}$ Department of Nursing, College of Medicine, University of Ibadan, PMB 5116, Ibadan, Nigeria
}

Correspondence should be addressed to Victor Olufolahan Lasebikan, victorlash@yahoo.com

Received 29 December 2011; Accepted 29 January 2012

Academic Editor: M. Estryn-Behar

Copyright ( 2012 V. O. Lasebikan and M. O. Oyetunde. This is an open access article distributed under the Creative Commons Attribution License, which permits unrestricted use, distribution, and reproduction in any medium, provided the original work is properly cited.

Objective. To evaluate the prevalence and associated factors of burnout among nurses in a Nigerian general hospital. Methods. A total sampling method was utilized. Measurements. Burnout was evaluated using the Maslach Burnout Inventory; GHQ-12 was used to determine the presence of psychiatric morbidity. Results. A high level of burnout was identified in $39.1 \%$ of the respondents in the area of emotional exhaustion (EE), $29.2 \%$ in the area of depersonalization and $40.0 \%$ in the area of reduced personal accomplishment. Multivariate analysis showed that doctor/nurse conflict (OR $=3.1,95 \% \mathrm{CI}: 1.9-6.3)$, inadequate nursing personnel $(\mathrm{OR}=2.6,95 \% \mathrm{CI}: 1.5-5.1)$, and too frequent night duties $(\mathrm{OR}=3.1,95 \% \mathrm{CI}: 1.7-5.6)$ were predictors of burnout in the area of $\mathrm{EE}$, doctor/nurse conflict $(\mathrm{OR}=3.4,95 \% \mathrm{CI}: 2.2-7.6)$ and too frequent night duties $(\mathrm{OR}=2.4,95 \% \mathrm{CI} 1.5-4.8)$ in the area of $\mathrm{D}$, high nursing hierarchy $(\mathrm{OR}=2.7,95 \% \mathrm{CI}: 1.5-4.8)$, poor wages $(\mathrm{OR}=2.9,95 \% \mathrm{CI}: 1.6-5,6)$, and too frequent night duties $(\mathrm{OR}=2.3,95 \% \mathrm{CI}: 2.3-4.5)$ in the area of RPA. Conclusions. Prevalence of burnout among these nurses was high. The government therefore needs to look into factors that will enhance nurses' recruitment and retention for effective health care delivery system.

\section{Introduction}

The burnout syndrome is a serious consequence of chronic exposure to work-related stressors. The construct of burnout syndrome appeared for the first time around the early 1970s, aimed at explaining the process of physical and mental deterioration in professionals working in areas such as teaching, health care, social work, or emergency legal services [1]. Subsequently, burnout syndrome was defined as a sustained response to chronic work stress comprising three dimensions: the experience of being emotionally exhausted (emotional exhaustion), negative attitudes and feelings toward the recipients of the service (depersonalization), and feelings of low accomplishment and professional failure otherwise known as lack of personal accomplishment [2].

Among nurses, the incidence of occupational stressrelated burnout is high and factors such as age of the nurse, years of service, hierarchy of nurse [3], lack of adequate staff, difficult or demanding patients [4], younger age, male gender, and inadequate clinical supervision [5] have been reported to be associated with burnout. Others are excess workload, emotional stress, unevaluated work and underpayment [6], poor leadership, death and dying, conflicts with staff, accepting responsibility, lack of social support, conflict with other nurses, conflict with physicians, presence of stressors related to private life, feeling that the job is threatened, and higher nursing grade [7].

Similarly, Kingdom [8] noted that excess workload and number of people living in the household were the best predictors of physical health problems among nurses in Japan, while likelihood to leave the current nursing position and lack of support in the workplace were the best predictors of mental problems. Stress is a factor that affects nurses on a daily basis and can result in nurses' absenteeism and aggression as well as reduced productivity and efficiency [8]. Burnout has a special significance in health care settings where staff experience both emotional and physical stress.

A growing recognition of job stress leading to dissatisfaction among registered nurses in Nigerian hospitals has 
contributed to current problems with recruitment and retention of nurses in the country in general but more peculiar in some states. If nurse administrators identify factors influencing nurses' job satisfaction in government hospitals and implement strategies to address these factors, nurses' turnover rate will decrease and recruitment and retention rates will increase. Moreover, burnout among nurses has a negative effect on the quality of patient care $[9,10]$.

Several studies have demonstrated various components of burnout among nurses in developed countries of the world $[7,8,11]$. However, not much has been done in a poor resource, multiethnic, and culturally laden country like Nigeria. There is a dearth of information on this subject matter, hence the need for this study.

\section{Study Area}

The study took place at the State Hospital, Ring Road, Ibadan. Ibadan is the capital of Oyo state, Nigeria, and it is the third largest city in Nigeria. The city is located in the southwestern part of the country. It has a population of over 3.5 million people. Ibadan is divided into eleven local government areas [12]. The hospital is owned by the State Government and it attends to all medical, surgical, and psychiatric cases. There are two hundred and ninety-two (292) nurses working in the hospital. Skill mix is not practiced in this hospital. Patient flow is quite high cutting across all social strata.

\section{Methodology}

3.1. Data Collection. There were two sources of data. The first was existing hospital records while the second was a survey. Ethical approval was obtained in February, 2008 from the ethical review committee of the Oyo State Ministry of Health. For the survey, individual letters were written to all nurses working at Ring Road State Hospital Ibadan in April, 2008, to inform and request for their participation in the study. A total sampling method was utilized. Consent was obtained from each participant and information obtained was made anonymous.

Information about the number of nurses and their status, attending doctors, coverage of all shifts by doctor on call, and patient-to-nurse ratio was obtained from the hospital documents.

\section{Survey Instrument}

The second document was a self-administered questionnaire divided into four parts. Part 1 included basic demographic data (age, sex, marital status, number of children, religion, and time to reach their hospital) and some questions about experiences during the past month (number of night shifts and conflict with other nurses or with doctors).

Part 2 consisted of the 12-item GHQ [13] and the Maslach Burnout Inventory (MBI) [14]. All survey instruments were individually handed over to the participants during a monthly staff screening exercise after each of them had received individual code only known to the research team members. This coding system enabled participants to be contacted after the study for those who required intervention.

The GHQ is a screening instrument for psychiatric morbidity. Although it does not yield a diagnosis, positive scores are indicative of psychological distress. Each item is rated either 0 or 1 on the basis of the frequency with which the subject has experienced the symptom in the recent past, yielding a maximum score of 12. A score of 1 or above is suggestive of psychological distress; however, to increase specificity, a cut-off point of 2 was used and score of 2 was used as positive screen.

Maslach Burnout Inventory (MBI) is a 22-item selfreport inventory designed to measure the characteristics of burnout. It has a dual column response format. The frequency column has a 6-point Likert-type format and the intensity column is 7 points.

Direct scoring was used for the items of the Emotional Exhaustion (EE) and Depersonalization (D) Subscales by adding together the values of the ratings shaded while reverse scoring was used for the item of the Personal Accomplishment (P) Subscale by adding together the reversed values of the shaded ratings. Low score represents presence of burnout, while high score represents absence of burnout. All subsections were added together for overall score. The Maslach Burnout Inventory has cross-cultural reliability and validity, and, in Nigeria, a study aimed at establishing the psychometric properties of the MBI using a sample of health care workers obtained reliability coefficients as follows: Cronbach's alpha of 0.86 and split-alpha of 0.57 [15].

\section{Pilot Test}

These survey instruments were pilot tested among 30 nurses from Adeoyo Maternity Hospital, a sister hospital also being run by the same board as the study center. This was to assess the applicability of instruments and suitability of study design. The pilot study showed that the design of the study was appropriate to the study population.

\section{Statistical Analysis}

All statistics were performed with SPSS 13.0 software [16]. Initially, bivariate analyses compared certain demographic variables such as gender, age, and hierarchy with high burnout. Pearson's chi-square was used to compare categorical variables, while $t$-test was used to compare two continuous variables and two-way ANOVA for more than two continuous variables.

For multivariate risk analysis of high burnout variables that were significant during bivariate analysis were entered into the model of the logistic regression equation. Variables were entered in the binary form, that is, 0,1 , and were coded in a way to illustrate the effect of each level. To facilitate the interpretation of odds ratio, a reference category was always chosen for the independent variables with which other variables could be compared. 
TABLE 1: Demographics variables of all respondents.

\begin{tabular}{|c|c|c|}
\hline Variable & No & Frequency $(\%) /$ mean \\
\hline Number & 270 & 100 \\
\hline Age, yr $($ mean $\pm S D)$ & - & $38.3 \pm 19.9$ \\
\hline$>$ mean & 181 & 67.0 \\
\hline Women & 173 & 64.1 \\
\hline Married or with a partner & 189 & 70.0 \\
\hline Number of children $\geq 1$ & 163 & 60.3 \\
\hline Practicing Christianity & 141 & 52.2 \\
\hline Traveling time to work, min $($ mean $\pm \mathrm{SD})$ & - & $35.9 \pm 19.6$ \\
\hline \multicolumn{3}{|l|}{ Status } \\
\hline Chief Nursing Officer, & 91 & 33.7 \\
\hline Assistant Chief Nursing Officer & 72 & 26.7 \\
\hline Principal Nursing Officer & 44 & 16.3 \\
\hline Senior Nursing Officer & 31 & 11.5 \\
\hline Nursing Officer & 22 & 8.2 \\
\hline Staff Nurse & 10 & 3.7 \\
\hline Working hours per week, (mean \pm SD) & - & $48.2 \pm 8.2$ \\
\hline Night shift in days per month, mean \pm SD & - & $19.6 \pm .11 .4$ \\
\hline$>$ mean night shift in/month days & 101 & 30.0 \\
\hline Mean shift allowance p/a in US dollars & - & $240 \pm 120$ \\
\hline Mean total salary in US dollars & - & $2400 \pm 1800$ \\
\hline Regularity of salary (Yes) & 4 & 1.5 \\
\hline $\mathrm{GHQ}+$ & 110 & 40.7 \\
\hline
\end{tabular}

TABle 2: Prevalence of burnout.

\begin{tabular}{|c|c|c|c|c|c|c|c|c|}
\hline \multicolumn{3}{|c|}{ Emotional exhaustion (EE) } & \multicolumn{3}{|c|}{ Depersonalization (D) } & \multicolumn{3}{|c|}{ Reduced personal accomplishment } \\
\hline$n(\%)$ & $n(\%)$ & $n(\%)$ & $n(\%)$ & $n(\%)$ & $n(\%)$ & $n(\%)$ & $n(\%)$ & $n(\%)$ \\
\hline Low & Moderate & High & Low & Moderate & High & Low & Moderate & High \\
\hline$\leq 18$ & $19-26$ & $\geq 27$ & $\leq 5$ & $6-9$ & $\geq 10$ & $\geq 40$ & $39-34$ & $\leq 33$ \\
\hline \multirow[t]{2}{*}{$164(60.9 \%)$} & $61(18.7 \%)$ & $55(20.4 \%)$ & $191(70.8 \%)$ & $36(13.3 \%)$ & $43(15.8 \%)$ & $162(60.0 \%)$ & $45(16.7 \%)$ & $63(23.3 \%)$ \\
\hline & $\begin{array}{c}\text { Burnout } \\
\text { (EE) }\end{array}$ & & & $\begin{array}{c}\text { Burnout } \\
\text { (D) }\end{array}$ & & & $\begin{array}{c}\text { Burnout } \\
\text { (RPA) }\end{array}$ & \\
\hline No & & Yes & No & & Yes & No & & Yes \\
\hline$n(\%)$ & & $n(\%)$ & $n(\%)$ & & $n(\%)$ & $n(\%)$ & & $n(\%)$ \\
\hline $164(60.9)$ & & $106(39.1)$ & $191(70.8)$ & & $79(29.2 \%)$ & $162(60.0)$ & & $108(40.0)$ \\
\hline
\end{tabular}

$\chi^{2}=8.2 . P<0.01$.

\section{Results}

A total of 270 of the $292(92.3 \%)$ nurses participated.

7.1. Characteristics. Table 1 summarizes the characteristics of the respondents. They were 270 in all, $64.1 \%$ were women, all $(100 \%)$ were practicing a religion, $70 \%$ were married, and only $10 \%$ were staff nurses. The mean age was $38.3 \pm$ 19.9 years. One hundred and ten $(40.7 \%)$ scored positive on GHQ.

7.2. Prevalence of Burnout. A high level of burnout was identified in $39.1 \%$ of the respondents in the area of emotional exhaustion (EE), 29.2\% in the area of depersonalization, and
$40.0 \%$ in the area of reduced personal accomplishment; this was significant $\chi^{2}=8.4 \mathrm{df}$ (2) $P=0.01$ (Table 2).

7.3. Prevalence of Burnout and Associated Factors. Older nurses $(P<0.01$, female gender $(P<0.01)$, being unmarried $(P<0.01)$, junior nursing hierarchy $(P<0.01)$, nurse/doctor conflict $(P<0.01)$, and too frequent night duties $(P<0.01)$ were significantly associated with high burnout in all the three dimensions (Table 3 ).

Nonavailability of a doctor to work with $(P<0.02)$ was significantly associated with burnout in the area of emotional exhaustion and depersonalization and also in the area of reduced personal accomplishment $(P<0.01)$ (Table 3$)$. 
TABLE 3: Sociodemographic characteristics and burnout.

\begin{tabular}{|c|c|c|c|c|c|c|c|c|c|c|}
\hline Variable & $N$ & $\mathrm{EE}$ & $\%$ & sig & $\mathrm{D}$ & $\%$ & sig & RPA & $\%$ & sig \\
\hline & & $n=106$ & & & $N=79$ & & & $N=108$ & & \\
\hline Age $\leq 38.3$ & 51 & 7 & 9.8 & \multirow{2}{*}{$<0.01$} & 6 & 11.8 & \multirow{2}{*}{$<0.01$} & 7 & 13.7 & \multirow{2}{*}{$<0.01$} \\
\hline Age $>38.3$ & 219 & 99 & 45.2 & & 71 & 32.4 & & 101 & 46.1 & \\
\hline Male & 97 & 27 & 27.8 & \multirow{2}{*}{$<0.01$} & 19 & 19.6 & \multirow{2}{*}{$<0.01$} & 26 & 26.8 & \multirow{2}{*}{$<0.01$} \\
\hline Female & 173 & 79 & 64.2 & & 60 & 34.7 & & 82 & 47.4 & \\
\hline Married or with partners & 189 & 37 & 19.6 & \multirow{2}{*}{$<0.01$} & 39 & 20.6 & \multirow{2}{*}{$<0.01$} & 33 & 17.5 & \multirow{2}{*}{$<0.01$} \\
\hline Unmarried & 81 & 69 & 85.1 & & 40 & 49.3 & & 75 & 92.6 & \\
\hline No children & 107 & 46 & 43.0 & \multirow{2}{*}{0.3} & 40 & 47.3 & \multirow{2}{*}{0.02} & 36 & 33.6 & \multirow{2}{*}{0.08} \\
\hline$\geq 1$ Children & 163 & 60 & 36.8 & & 39 & 23.9 & & 72 & 44.2 & \\
\hline Traveling time to work (mins) $\leq 35.9$ & 201 & 76 & 37.8 & \multirow{2}{*}{0.4} & 62 & 30.8 & \multirow{2}{*}{0.3} & 78 & 38.8 & \multirow{2}{*}{0.5} \\
\hline Traveling time to work (mins) $>35.9$ & 69 & 30 & 43.5 & & 17 & 24.6 & & 30 & 43.5 & \\
\hline Status: CNO/ACNO/PNO & 205 & 70 & 34.1 & \multirow{2}{*}{$<0.01$} & 45 & 21.9 & \multirow{2}{*}{$<0.01$} & 70 & 34.1 & \multirow{2}{*}{$<0.01$} \\
\hline Status: SNO/NO/Staff Nurse & 65 & 36 & 55.4 & & 34 & 52.3 & & 38 & 58.4 & \\
\hline Nurse/nurse role conflict (yes) & 80 & 36 & 45.0 & \multirow{2}{*}{0.2} & 24 & 30.0 & \multirow{2}{*}{0.7} & 36 & 45.0 & \multirow{2}{*}{0.3} \\
\hline Nurse/nurse role conflict (no) & 190 & 70 & 36.8 & & 53 & 27.9 & & 72 & 37.9 & \\
\hline Nurse/doctor role conflict (yes) & 120 & 63 & 52.5 & \multirow{2}{*}{$<0.01$} & 45 & 37.5 & \multirow{2}{*}{$<0.01$} & 75 & 62.5 & \multirow{2}{*}{$<0.01$} \\
\hline Nurse/doctor role conflict (no) & 150 & 43 & 28.7 & & 34 & 22.7 & & 33 & 22.0 & \\
\hline Availability of physicians to work with (yes) & 34 & 7 & 20.6 & \multirow{2}{*}{$<0.02$} & 4 & 11.8 & \multirow{2}{*}{0.02} & 7 & 20.6 & \multirow{2}{*}{0.01} \\
\hline Availability of physicians to work with (no) & 236 & 99 & 41.9 & & 75 & 31.8 & & 101 & 42.8 & \\
\hline Lack or inadequate nursing personnel (yes) & 93 & 22 & 23.7 & \multirow{2}{*}{$<0.01$} & 17 & 18.3 & \multirow{2}{*}{$<0.01$} & 20 & 21.5 & \multirow{2}{*}{$<0.01$} \\
\hline Lack or inadequate nursing personnel (no) & 177 & 84 & 47.5 & & 62 & 35.0 & & 88 & 49.7 & \\
\hline Poor Wages (yes) & 249 & 103 & 41.4 & $<0.02$ & 77 & 30.9 & 0.04 & 103 & 41.4 & 0.01 \\
\hline Poor Wages (no) & 21 & 3 & 14.3 & $<0.02$ & 2 & 9.5 & 0.04 & 5 & 7.0 & 0.01 \\
\hline Too frequent night duties (yes) & 187 & 90 & 48.1 & $<0.01$ & 70 & 37.4 & $<0.01$ & 92 & 49.1 & $<0.01$ \\
\hline Too frequent night duties (no) & 83 & 16 & 19.2 & $<0.01$ & 9 & 10.8 & $<0.01$ & 16 & 19.2 & $<0.01$ \\
\hline Inadequate security during night duty (yes) & 260 & 104 & 40.0 & $0.2^{*}$ & 76 & 29.2 & $0.9^{*}$ & 106 & 40.8 & 0.2 \\
\hline Inadequate security during night duty (no) & 10 & 2 & 20.0 & 0.2 & 3 & 30.0 & 0.9 & 2 & 20.0 & 0.2 \\
\hline
\end{tabular}

* Fisher's Exact.

EE: Emotional exhaustion; D: depersonalization; R: reduced Personal accomplishment.

Poor wages were significantly associated with burnout in the area of emotional exhaustion $(P<0.02)$, in the area of depersonalization $(P=0.04)$, and in the area of reduced personal accomplishment $(P=0.01)$ (Table 3$)$.

7.4. Risk Factors for Burnout: Multivariate Analysis. Multivariate analysis showed that doctor/nurse conflict $(\mathrm{OR}=3.1$, 95\% CI: $1.9-6.3$ ), low doctor/nurse ratio $(\mathrm{OR}=6.1,95 \% \mathrm{CI}$ : 2.5-13.2), inadequate nursing personnel $(\mathrm{OR}=2.6,95 \% \mathrm{CI}$ : 1.5-5.1), and too frequent night duties ( $\mathrm{OR}=3.1,95 \% \mathrm{CI}$ : 1.7-5.6) were predictors of burnout in the area of emotional exhaustion and doctor/nurse conflict $(\mathrm{OR}=3.4,95 \% \mathrm{CI}$ : 2.2-7.6), low doctor/nurse ratio $(\mathrm{OR}=2.4,95 \% \mathrm{CI}: 1.4-$ 4.1 ), and too frequent night duties ( $\mathrm{OR}=2.4$, 95\% CI: $1.5-$ $4.8)$ in the area of depersonalization. High nursing hierarchy $(\mathrm{OR}=2.7,95 \% \mathrm{CI}: 1.5-4.8)$, poor wages $(\mathrm{OR}=2.9,95 \%$ CI: $1.6-5.6)$, and too frequent night duties ( $\mathrm{OR}=2.3,95 \%$ CI: 2.3-4.5) in the area of reduced personal accomplishment were associated with high burnout after model adjustment (Table 4).

\section{Discussion}

Burnout appears to be highly prevalent among nurses in this hospital. These subjects also have high prevalence of psychiatric morbidity. Our study has demonstrated a significant difference in the prevalence of burnout across the three dimensions. There were also demographic variations in the prevalence of burnout among these nurses across these burnout dimensions. These demographic differences were present for age, gender, and marital status. We found that high burnout was significantly reported by older nurses, a finding previously reported [17] but which contrasts an earlier one [5]. As previously reported [17-19], we also found that junior nursing hierarchy was significantly associated with high burnout. This appears paradoxical as the senior nurses are expected to have reported more burnout compare $\mathrm{d}$ with junior ones since the senior ones should be older in age. This result may not be unassociated with bullying in nursing which is fast becoming a common practice [20, 21]. More women reported high burnout in this study contrast to that of Edwards and colleagues [5] although the same has been 
TABLE 4: Significant predictors of burnout among nurses.

\begin{tabular}{lcccccc}
\hline Variables & EE & Sig & D & Sig & RPA & Sig \\
\hline Very senior nurses & NS & & NS & & $2.7(1.5-4.8)$ & 0.03 \\
Doctor/nurse role conflict & $3.1(1.9-6.3)$ & 0.03 & $3.4(2.2-7.6)$ & 0.03 & NS & \\
Inadequate number of physicians to work with & $6.1(2.5-13.2)$ & $<0.01$ & $2.4(1.4-4.1)$ & 0.03 & NS & \\
Inadequate nursing personnel & $2.6(1.5-5.1)$ & 0.03 & NS & & NS & \\
Poor (Wages) & NS & & NS & & $2.9(1.6-5.6)$ & 0.03 \\
Too frequent night duties & $3.1(1.7-5.6)$ & 0.03 & $2.4(1.5-4.8)$ & 0.03 & $2.3(1.4-4.5)$ & 0.03 \\
\hline
\end{tabular}

EE: emotional exhaustion; D: depersonalization; RPA: reduced personal accomplishmen.

reported even among other professional such as physicians [22].

Our study also suggests that marriage is a protective factor against high burnout. The present study was not able to corroborate an earlier one in Japan [8] which reported that number of people living in the household is the best predictor of burnout among nurses.

We found that nurse/doctor conflict and nonavailability of physicians to work with were associated with burnout. Stehle [23] similarly noted that many of the stressors identified among nurses concerned working relationships with doctors. The potential explanation for this association in the present study is that nonavailability of physicians to work with would require the nurses to pay additional attention to the patients in order to "cover up" for the doctor's absence thereby creating additional strain for them. This singular factor underscores the importance of team building in the prevention of burnout in nurses.

We did not find an association between burnout and number of children or other personal factors but found that organizational factors, too frequent night shifts, poor wages, and inadequate security at night, were associated with high burnout. One of the reasons why inadequate security at night could have been associated with high burnout is increased risk to physical injuries and assaults. For Maslach and colleagues [24], burnout is a response to overload and some of the factors retained after model adjustment during multivariate analysis were as a result of work overload. It has been suggested that reducing hours may be the first step to reduce resident burnout [25] and this is applicable to nurses.

In our multivariate analysis, as previously reported [2628], all the predictors of burnout among the nurses were essentially organizational factors (doctor/nurse conflict, inadequate number of physicians to work with, inadequate nursing personnel, and too frequent night duties), suggesting the need for organizational restructuring of the health services of the Oyo state if prevalence of burnout among the nurses is to reduce. There is an increased likelihood for illness and injury among employees working in long-hour schedules and schedules involving unconventional shift work (e.g., night and evening shifts). These issues are of utmost ethical import taking into consideration fatigue-related errors such employees working in these kind of demanding schedules may be liable. Such errors could have serious and adverse repercussions for public safety [29]. Thus, the result from this study indicating the association between too frequent night duties and burnout is of utmost ethical consideration considering the medical errors that could accrue from such practice.

The prevalence of psychiatric morbidity reported in this study high is close to that of burnout in the areas of emotional exhaustion and reduced personal accomplishment illustrating that although burnout is not a recognized clinical psychiatric or psychological disorder, there are some similar features between burnout and diagnosable conditions such as depression, anxiety disorders, or mood disorders [30]. Similar high prevalence of psychiatric symptoms has been reported in other parts of the world among nurses [31, 32].

A major strength of this study is that this is the first study to our best knowledge of the largest nursing workforce in Nigeria. Although the study was limited to one of the hospitals being managed by an umbrella board, findings from this study may be generalized to other general hospitals in the state.

The present study has a number of potential limitations: our aim was to focus on the individuals (nurses) rather than on the patients themselves, thus patients' factors and interdepartmental differences were not included in the analysis. We also did not study various coping strategies employed by these nurses. We were not also able to correlate the GHQ score with level of burnout. These should be considered in future studies.

\section{Conflict of Interests}

None of the authors has any financial relationship with a commercial entity that has an interest in the subject of this paper.

\section{Acknowledgments}

Acknowledgment is given to the Director of Ethical Review Board of the Oyo State Ministry of Health for granting ethical approval to undertake this study. The assistance of Dr. A. Akinnuoye, Dr. O. Ayinde, Dr. O. Ojediran, Sola Ogundeji, and Christie Alabi in data collection is also appreciated. The authors acknowledge the funding support of New World Psychiatric Hospital, Ibadan. 


\section{References}

[1] H. J. Freudenberger, "Staff burnout," Journal of Social Issues, vol. 30, no. 1, pp. 159-165, 1974.

[2] C. Maslach and S. Jackson, Maslach Burnout Inventory Manual, Consulting Psychologists Press, Mountain View, Calif, USA, 1996.

[3] V. A. Lambert, C. E. Lambert, and M. Ito, "Workplace stressors, ways of coping and demographic characteristics as predictors of physical and mental health of Japanese hospital nurses," International Journal of Nursing Studies, vol. 41, no. 1, pp. 85-97, 2004.

[4] R. Jenkins and P. Elliott, "Stressors, burnout and social support: nurses in acute mental health settings," Journal of Advanced Nursing, vol. 48, no. 6, pp. 622-631, 2004.

[5] D. Edwards, P. Burnard, B. Hannigan et al., "Clinical supervision and burnout: the influence of clinical supervision for community mental health nurses," Journal of Clinical Nursing, vol. 15, no. 8, pp. 1007-1015, 2006.

[6] R. Vimantaite and A. Seskevicius, "The burnout syndrome among nurses working in Lithuanian cardiac surgery centers," Medicina, vol. 42, no. 7, pp. 600-605, 2006.

[7] S. Stordeur, W. D’hoore, and C. Vandenberghe, "Leadership, organizational stress, and emotional exhaustion among hospital nursing staff," Journal of Advanced Nursing, vol. 35, no. 4, pp. 533-542, 2001.

[8] B Kingdom and F. Halovorsen, "Peri-operative nurses' perceptions of stress in the workplace," AORN Journal, 2008, http:// findarticles.com/p/articles/mi_m0FSL/is_4_84/ai_n27015570/.

[9] J. D. McCue, "The effects of stress of physicians and their medical practice," The New England Journal of Medicine, vol. 306, no. 8, pp. 458-463, 1982.

[10] T. D. Shanafelt, K. A. Bradley, J. E. Wipf, and A. L. Back, "Burnout and self-reported patient care in an internal medicine residency program," Annals of Internal Medicine, vol. 136, no. 5, pp. 358-367, 2002.

[11] R. F. AbuAlRub, "Job stress, job performance, and social support among hospital nurses," Journal of Nursing Scholarship, vol. 36, no. 1, pp. 73-78, 2004.

[12] Ruaf Foundation, Ibadan, 2010, http://www.ruaf.org/.

[13] D. Goldberg and P. Williams, Users Guide to the General Health Questionnaire, NFER-NELSON, London, UK, 1988.

[14] C Maslach, S. E. Jackson, and M. P. Leiter, Maslach Burnout Inventory Manual, Consulting Psychologists Press, Palo Alto, Calif, USA, 3rd edition, 1996.

[15] O. A. Coker and P. F. Omoluabi, "Validation of maslach burnout inventory," IFE Psychologia, vol. 17, article 1, 2009.

[16] Statistical Package for Social Studies, SPSS, Chicago, Ill, USA, 2011.

[17] R. Quatrrin, A. Zaanni, E. Nascig, and M. Annunciate, "Level of Burnout among nurses working in Oncology in an Italian region," Oncology Nursing Forum, vol. 33, no. 40, pp. 815-820, 2006.

[18] J. Firth-Cozens, "Sources of stress in women junior house officers," British Medical Journal, vol. 301, no. 6743, pp. 89-91, 1990.

[19] M. Estryn-Béhar, B. I. J. M. van der Heijden, H. Ogiñska et al., "The impact of social work environment, teamwork characteristics, burnout, and personal factors upon intent to leave among European nurses," Medical Care, vol. 45, no. 10, pp. 939-950, 2007.

[20] R. Hader, "Workplace Violence Survey 2008. Unsettling findings: employees safety isn't the norm in our healthcare settings," Nursing Management, vol. 39, no. 7, pp. 13-19, 2008.
[21] S. L. Johnson and R. E. Rea, "Workplace bullying: concerns for nurse leaders," Journal of Nursing Administration, vol. 39, no. 2, pp. 84-90, 2009.

[22] N. K. Thomas, "Resident burnout," Journal of the American Medical Association, vol. 292, no. 23, pp. 2880-2889, 2004.

[23] J. L. Stehle, "Critical care nursing stress: the findings revisited," Nursing Research, vol. 30, no. 3, pp. 182-186, 1981.

[24] C. Maslach, W. B. Schaufeli, and M. P. Leiter, "Job burnout," Annual Review of Psychology, vol. 52, pp. 397-422, 2001.

[25] R. Gopal, J. J. Glasheen, T. J. Miyoshi, and A. V. Prochazka, "Burnout and internal medicine resident work-hour restrictions," Archives of Internal Medicine, vol. 165, no. 22, pp. 25952600, 2005.

[26] F. H. Decker, "Occupational and nonoccupational factors in Job satisfaction and psychological distress among nurses," Research in Nursing and Health, vol. 20, no. 5, pp. 453-464, 1997.

[27] M. Elovainio and M. Kivimäki, "Occupational stresses, goal clarity, control, and strain among nurses in the finnish health care system," Research in Nursing and Health, vol. 19, no. 6, pp. 517-524, 1996.

[28] V. Lee and M. C. Henderson, "Occupational stress and organizational commitment in nurse administrators," Journal of Nursing Administration, vol. 26, no. 5, pp. 21-28, 1996.

[29] A. E. Dembe, "Ethical issues relating to the health effects of long working hours," Journal of Business Ethics, vol. 84, supplement 2, pp. 195-208, 2009.

[30] E. Scott, "The origins of burnout," 2006, http://stress.about .com/bio/elizabeth-scott-m-s17577.htm.

[31] Y. Q. Gao, B. C. Pan, and W. Sun, "Depressive symptoms among Chinese nurses: prevalence and the associated factors," Journal of Advanced Nursing, vol. 13, no. 4, pp. 468-474, 2011.

[32] M. L. Hseish, Y. M. Li, and E. T. Channg, "Sleep disorder in Taiwan Nurses: a random sample survey," Nursing \& Health Sciences, vol. 13, no. 4, pp. 468-474, 2011. 


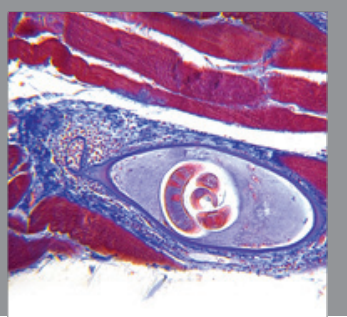

Gastroenterology

Research and Practice
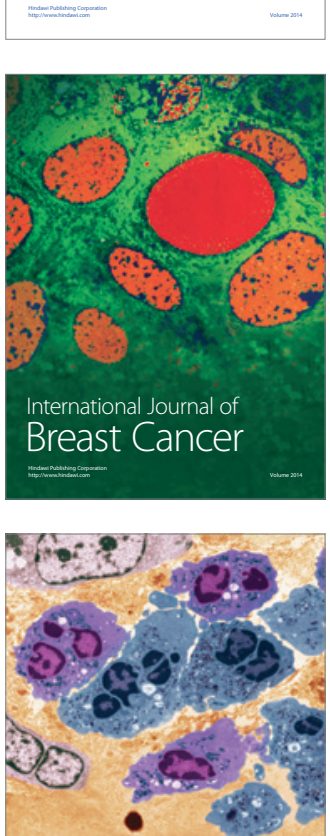

International Journal of Inflammation
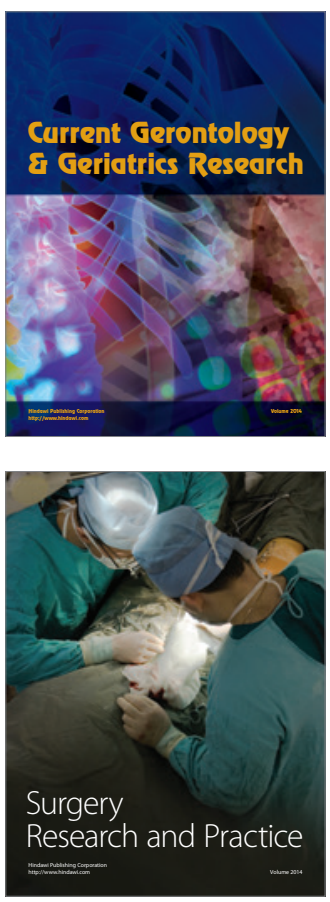
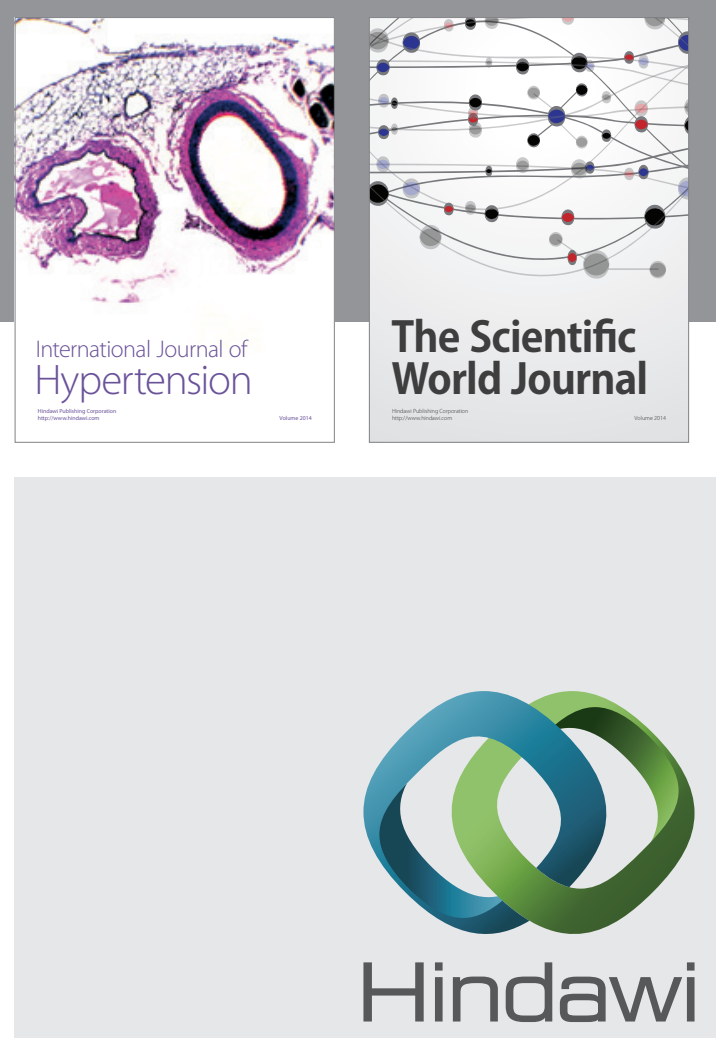

Submit your manuscripts at

http://www.hindawi.com
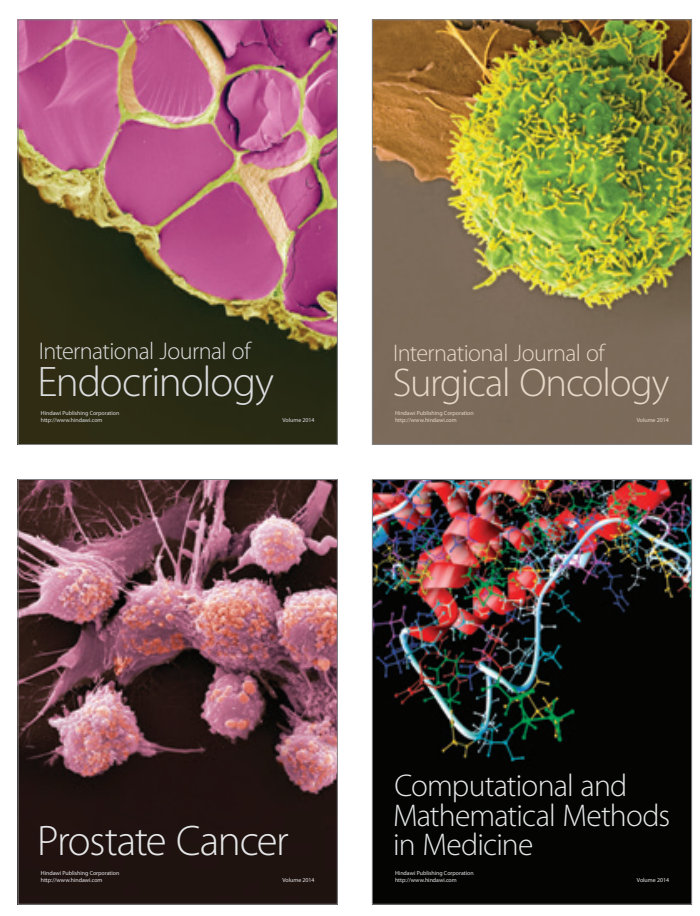
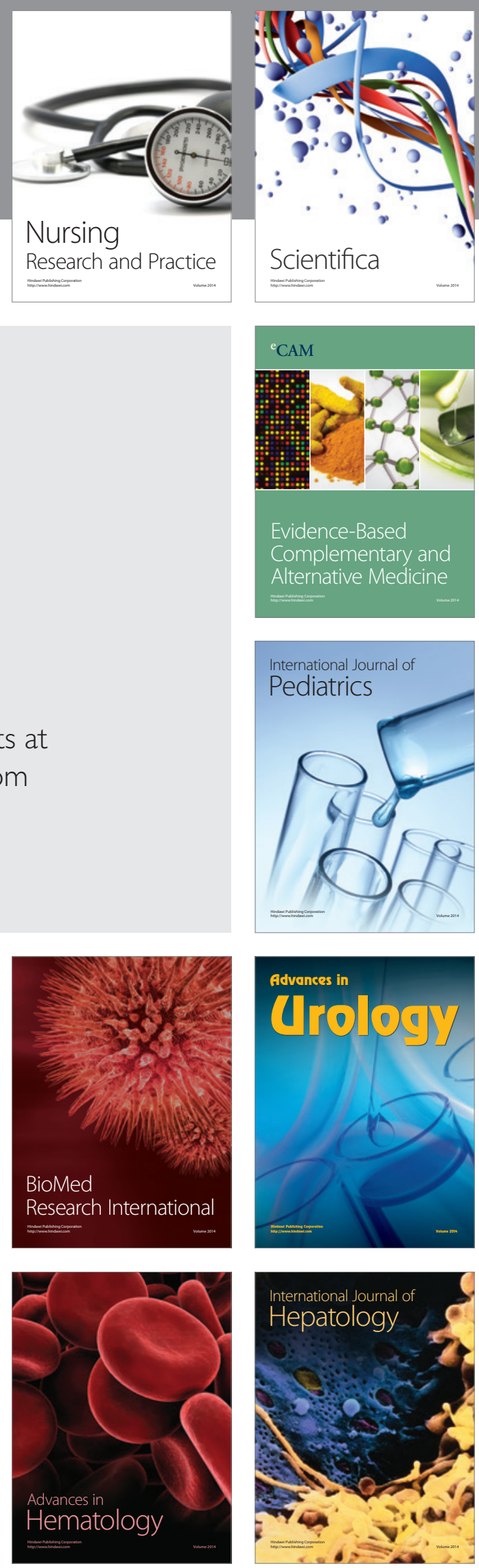